\title{
Business E-mail Writing with New Stylistic Features
}

\author{
Xiangmin LI, Wuyou WEI \\ Beijing International Studies University, Beijing, China
}

\begin{abstract}
Business E-mail is an important communication tool in foreign business activities. Particularly, in today's Big Data era, the realization of "paperless trade" mainly relies on business E-mail communication. Based on relevant theories of stylistics and pragmatics, and supported by E-mail samples collected from a foreign exhibition company in Beijing, this paper tries to further study the stylistic features of business E-mail in its vocabulary, sentence pattern, mood, and structure and analyze its para-language and multimedia features in the hope of promoting professional business E-mail writing as well as effective international business communication.
\end{abstract}

KEYWORD: E-mail writing; stylistic; para-language; multimedia

\section{INTRODUCTION}

As an effective communication tool in international business, the penetration function of business E-mail is more significant nowadays. Due to its distinct advantages of low cost, fast transmission speed and strong popularity among worldwide users, business E-mail has become the first choice for companies to make connection with their international clients. In addition to its function in spreading information, business E-mail also plays a role in improving effective communication by using texts, pictures, video, hyperlinks and other multimedia tools. Therefore, for businessperson as well as business English learners who have already acquired professional business knowledge, successful E-mail writing will not only enhance individual communication capability but also improve the image and international level of their enterprises. Based on theories of stylistics and pragmatics and supported by E-mail samples collected from a foreign exhibition company in Beijing, this paper tries to make further discussion about the stylistic features of business E-mail in its vocabulary, sentence pattern, mood and structure and particularly, analyze its para-language and multimedia features under the Internet background. It is hoped that this will improve professional business E-mail writing as well as effective international business communication.

\section{FOUR MAIN WRITING RULES}

\subsection{Vocabulary: abide by the "Quantity Principle"}

American linguist H.P. Grice (1975) put forward a basic discourse principle and named it Cooperative Principle ( $\mathrm{CP}$ in short). It indicates that our conversation should be targeted and be relevant to the theme. One important principle in $\mathrm{CP}$ is called "Quantity Principle" —_ to make your conversation as informative as is required for the current purposes of the conversation and do not make your contribution more informative than is required. This indicates that one must abide by informative rules and highlight the exactness of vocabulary so as to make sure that the word would not lead to ambiguity, technically or professionally.

\subsubsection{Use midget words to express main ideas}

I hope you are well. My colleague has passed on your email to me. Sorry for the confusion, I will be your main contact in the Exhibition. Please feel free to contact me. Thanks!

In this example, the manager from Exhibition Organizer used just 32 midget words while clearly expressed four main information to his client: 1 . Warm salutation; 2. There were some changes about your main contact person in the Exhibition; 3. Apology for the personnel replacement; 4. Information about the new contact person. There are always uncertain changes when it comes to business. For instance, the change of venue, personnel or plans may occur unexpectedly and cause 
inconvenience towards parties concerned. So if one were able to express complicated changes in midget words, just as the example listed above, effective communication would be realized.

\subsubsection{Avoid heavy usage of abbreviations}

Rapid development on the Internet comes into being substantial cyber languages characterized by various abbreviations. For instance, we often use "BTW" for "By the way", "pls" for "Please" and "ASAP" for "As soon as possible" in daily communication on the Internet. And the business world is not an exception. However, such popularity of abbreviation does not mean that more abbreviations could lead to more effective and successful business.

The unit price for a $8 \mathrm{G}$ USB Key is approximately USD 7. The total amount is: 500 pcs $\mathrm{x}$ USD $7=$ USD 3, 500 (incl. VAT). The price may varies depends on the brand and memory capacity.

We check and confirm to you that we have this item available in our stock. Could you advise your T/P please?

Abbreviations like "pcs", "incl" and "VAT" in the Example 2 are short for "pieces", "including" and "value-added tax" respectively. All these words are welcomed here since they have already been defined as standard expression in international trade and would not cause any trade disputes. On the contrary, in Example 3, the abbreviation of "T/P" is not in line with the "Quantity Principle". In fact, receiver had to send another E-mail to inquiry the exact meaning of "T/P" so as to make sure the smooth operation of the business. Actually, the word "T/P" here refers to a professional trade term, namely, target price. In business, particularly, when it comes to business contract, specifications of goods or other sensitive information, an E-mail should always be written in full words instead of abbreviations.

\subsection{Sentence: use more Simple sentence and passive sentence}

Data collected from sample E-mails show that about 95\% sentences in business E-mail belong to simple one. And it is frequently used at the end of each business E-mail. For instance:

Looking forward to hearing from you soon.

Please feel free to contact me.

I will keep you informed on any updates.

Thanks for your help and I look forward to your response.

Another crucial rule in Cooperative Principle is called the "Quality Principle", which means that "you should try to make your contribution one that is true and do not say things you believe to be false or do not say things for which you lack adequate evidence". It means that one should make sure the "realness" and "objectiveness" of the information. And in business E-mail writing, it was found that passive sentence is often the preferred one to maintain this "objectiveness". Particularly, when spreading facts, news or similar objective information, like notice or announcement, one would better use passive sentence.

The latest exhibitor list is already added to the official website.

The relevant sales representatives are made aware of this important deadlines.

The quotation will have to be given upon your request.

Example 8 refers to the fact of exhibitor list; Example 9 shows the serious attitude and authority of a project director and Example 10 clearly declares the requirement of quotation. These examples on one hand, announce information clearly as well as show Organizer's attitude, and on the other hand, make sure the objective and professional content. Business contract, rules and regulations, specifications, meeting time or venue arrangements and other objective information in business E-mails should reduce the usage of first personal pronouns like "I" or "We" and attributive clauses characterized by linking word like "That". When writing business E-mail, we should always keep in mind the principles of spreading information clearly, objectively and rapidly by diminishing the usage of complicated or emotional sentences.

\subsection{Mood: use euphemism and subjunctive mood}

Politeness Principles advocated by Pragmatics linguist Leech (1983) indicate that politeness is a kind of behavior, which can build and maintain social unity; Politeness is an individual capability in relatively harmonious society. In the absence of face-to-face communication, the tone of E-mails plays a crucial role in finding out trade parties' attitude towards questions concerned. E-mail about invitation, congratulation, apology, claim, refusal or complaint contains various tones. But in spite of different forms of tones, there exists one common rule -- always be polite and harmonious in business communication.

\subsubsection{The usage of euphemism in alleviating negative information}

If there were to be a change then I would have to discuss with my manager and it would really affect the plans we have already started making.

Example 11 was an inquiry or rebuke about the change of arrangement made by the organizer. Due to this unexpected replacement, the exhibitor had to rearrange plans which had already been made and that would of course result in inconvenience in business activities. Instead of harsh rebuke or 
repeated blame, this E-mail adopted two euphemism words - Would to express its attitude in a moderately polite tone.

The Sympathy Maxim in the Politeness Principle advocates to minimize antipathy between self and other and maximize sympathy between self and other: "When it comes to assessing the result of trade between business parties, we should pay attention to both the economic index and the relationship level." And a really successful business communication should contain three aspects: 1 . The establishment of business relationship; 2. The full realization of business agreements; 3 . The maintenance of well-arranged relationship. Therefore, in view of long-term business cooperation relationship, trade partners should abide by the Politeness Principles and choose more euphemism expressions and polite tone in saying negative information so as to ensure the smooth operation of business communication.

\subsubsection{The usage of subjunctive mood to express requirement}

Should you have any questions regarding the VIP Hosted Buyer Program, please do not hesitate to contact me.

I could accept your invitation to speak at the VIP Dinner if I were to miss the annual stockholders' meeting.

Example 12 was the ending of an E-mail sent by the director of the Exhibition to worldwide exhibitors. By using subjunctive mood -- Should have, formal manner and professional suggestions were delivered here. In Example 13, one exhibitor was sorry for his request of not being able to participate the VIP Dinner. Though this is an negative information, the usage of subjunctive words like "Could" and "Were to" successfully reduced the negative influence exerted on receiver and made his request more acceptable. In business communication, the usage of subjunctive mood is beneficiary to both the sender and receiver. It will enhance the formality as well as the politeness of the E-mail and make sure the harmonious running of business.

\subsection{Structure: use para-language and multimedia features}

Emerging para-language and multimedia features have been found in business E-mail structure..

\subsubsection{Use para-language features to enhance the clearness and vividness}

Huang Guowen (2005) said in his paper The Characteristics of e-discourse that there are some ways to express "Smileys". Here "Smileys" could also be referred to para-language features. They can vividly transmit more information and arouse receivers' interests or emotion. It maybe safe to say that para-language features show the informal side of E-mail. In business E-mail writing, the way to express para-language features could: 1 . Change the color or size of the word; 2 . Add network emoticons; 3. Revise the background of E-mail; 4. Add emotional pictures. For instance, one may add horizontal line or dot or font-weight to stress certain important information.

Hi Lynnor,

Thanks for keeping me updated.:-

I have attached my correspondence with PICO for some background for you -- I hope you can see where I'm trying to come from and the difficult in the responses I am receiving.

Regards,

- Furniture list, including codes from PICO list:

o 1 x lockable counter $(\mathrm{PN}-03)$

o 6 x bar stools (EC-12)

o $2 \times$ tall round tables $($ ET-10)

o 1 x coffee table (PF-11)

o 3 x black leather chairs (CC-05)

** The deadline for submitting your requests is 11am this Wednesday $10^{\text {th }}$ September. **

Dakujem, Thank you, Danke, regards,

Roderick ADJEI (Project manager)

In Example 14, a network emoticon ":), (17) used in a Russian exhibitor's E-mail, humorously showing his great thanks for services provided by the Organizer. And this smile emoticon indicates harmonious cooperation relation between the two trade parties. Example 15 was a furniture list about construction works in the exhibition venue. On the contrary to previously-used delicate and longparagraph description in every details, this E-mail just used three para-language symbols like “•” "o " " ( ) " to clearly show details in an orderly manner. Example 16 was an information with highimportance by attaching symbols like "**" " " and by changing the color of words so that receivers could find out the "Attention information" easily as soon as they receive it. In Example 17, three languages (Dakujem, Thank you, Danke) were used by sender to show his thanks or respect towards clients all over the world, which on the other hand publicize the globalization level of the enterprise.

Owing to the advantages of strong readability, obvious focus and orderly structure, these simple, small while vivid and interesting para-language features should be popularized among worldwide businessperson to enhance the exactness and vividness of business E-mail.

\subsubsection{Use multimedia features to improve quality information communication}

Multimedia features refer to the enrichment of an Email by adding pictures, audio texts, video, hyperlinker and other attachments so as to enable 
receivers more access to information. "The attachment function of E-mail brings great convenience to business communication: 1. High capacity of information; 2. Diversified format; 3. Easy access to edit the format of the text input" (Jiang Dawei, 2009). Besides the above mentioned features, it is also found in samples that many senior managers and project directors would like to attach personal signature and enterprise image, logo and website at the end of every E-mail sent out for further information.

Lynnor Account Manager

T: +44 (0) 1212345678 | M: +44 (0) 12345678

E: lynnor@abc.com |W: www.abc.com

A: Ludgate House, 245 Blackfriars Road, London, SE1 9UY

Please consider the environment before printing this E-mail

Alanna O'Grady | International Marketing

Support

PO Box 12345, Russley, Christchurch 0000

t. +123456789 | ext. 1234

e. Alanna.OGrady@airways.co.nz |

w. www.airways.co.nz

Example 18 was the ending of an E-mail sent out by a British manager to his Chinese partner. Clearly, a picture and one sentence attached at the end of the E-mail show this company's environmental mission -- Please consider the environment before printing this E-mail. This is a kind of network attachment with multimedia features and raises the company's image. In Example 19, the E-mail sent by a New Zealand manager added the website of the company for further information. These features, quantitatively or qualitatively, spread information effectively and vividly. Therefore, it is suggested that multimedia features should be made full use of in writing business E-mail to stimulate potential business.

\section{CONCLUSIONS}

Based on the above discussion, business E-mail writing with new stylistics features should be in accordance with the Politeness Principle and the "Quantity" and "Quality" rules in Cooperative Principles; should use more midget vocabulary and avoid ambiguous abbreviation so as to ensure the exactness; should choose simple sentence and passive sentence to keep the objectiveness and readiness; and should alleviate negative or emotional expressions by adopting more subjective mood and euphemism. When arranging the whole structure of a business E-mail, one should make sure the format clear, the word size standardized, and the information understandable. What's more important is to use diversified para-language and multimedia features to help raise effectiveness of business communication, publicize enterprise culture and create more room for future business cooperation.

\section{REFERENCES}

[1] Grice, H. P. 2001. Logic \& Conversation. In P. Cole \& J. L. Morgan. Syntax and Semantics, vol 3: Speech Acts. New York: Academic Press.

[2] Leech, N. G. 1993. Principles of pragmatics. London and New York: Longman Group Limited.

[3] Ronald B. Adler Jeanne Marquardt Elmhorst. 2005. Business Communication: Principles and Practice, the 8th Edition. Beijing: Beijing University Press.

[4] Hu Zhuanglin \& Liu Runqing \& Li Yanfu. 1988. The Course of Linguistics. Beijing: Beijing University Press

[5] Huang Guowen. 2005. The Characteristics of E-discourse. Foreign Language and Their Teaching.

[6] Li Junru. 2007. The Genre Analysis of Business English E-mail. Foreign Language and Their Teaching.

[7] Wang Zhihua. 2008. Discourse Analysis of Corporation English E-mail. Cultural Studies 